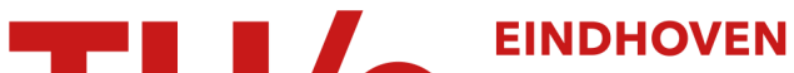 \\ UNIVERSITY OF \\ TECHNOLOGY
}

\section{On the kinetics of spatial atomic layer deposition}

\section{Citation for published version (APA):}

Poodt, P., Lieshout, van, J., Illiberi, A., Knaapen, R., Roozeboom, F., \& Asten, van, A. (2013). On the kinetics of spatial atomic layer deposition. Journal of Vacuum Science and Technology A: Vacuum, Surfaces, and Films, 31(1), [01A108]. https://doi.org/10.1116/1.4756692

DOI:

10.1116/1.4756692

Document status and date:

Published: 01/01/2013

\section{Document Version:}

Publisher's PDF, also known as Version of Record (includes final page, issue and volume numbers)

\section{Please check the document version of this publication:}

-A submitted manuscript is the version of the article upon submission and before peer-review. There can be important differences between the submitted version and the official published version of record. People interested in the research are advised to contact the author for the final version of the publication, or visit the $\mathrm{DOI}$ to the publisher's website.

- The final author version and the galley proof are versions of the publication after peer review.

- The final published version features the final layout of the paper including the volume, issue and page numbers.

Link to publication

\section{General rights}

Copyright and moral rights for the publications made accessible in the public portal are retained by the authors and/or other copyright owners and it is a condition of accessing publications that users recognise and abide by the legal requirements associated with these rights.

- Users may download and print one copy of any publication from the public portal for the purpose of private study or research.

- You may not further distribute the material or use it for any profit-making activity or commercial gain

- You may freely distribute the URL identifying the publication in the public portal.

If the publication is distributed under the terms of Article $25 \mathrm{fa}$ of the Dutch Copyright Act, indicated by the "Taverne" license above, please follow below link for the End User Agreement:

www.tue.nl/taverne

Take down policy

If you believe that this document breaches copyright please contact us at:

openaccess@tue.nl

providing details and we will investigate your claim. 


\title{
On the kinetics of spatial atomic layer deposition
}

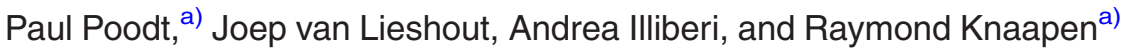 \\ TNO, P.O. Box 6235, 5600 HE Eindhoven, The Netherlands \\ Fred Roozeboom \\ TNO, P.O. Box 6235, 5600 HE Eindhoven, The Netherlands and Eindhoven University of Technology, \\ P.O. Box 513, 5600 MB Eindhoven, The Netherlands
}

Almie van Asten

TNO, P.O. Box 6235, 5600 HE Eindhoven, The Netherlands

(Received 2 August 2012; accepted 17 September 2012; published 10 October 2012)

\begin{abstract}
Spatial atomic layer deposition (ALD) is a promising technology for high deposition rate and high-throughput ALD that can be used for roll-to-roll and large-area applications. In an ideal spatial ALD reactor, the design of the injector should be tuned to the deposition kinetics of the ALD reaction, requiring an in-depth knowledge of the dependencies of the growth per cycle (GPC) on the main kinetic parameters. The authors have investigated the deposition kinetics of spatial ALD of alumina from trimethylaluminum and $\mathrm{H}_{2} \mathrm{O}$ at atmospheric pressure. A kinetic model was developed, which describes the growth per cycle as a function of the main kinetic parameters. The observation of a $\sqrt{t}$ time dependency in the GPC indicates that precursor diffusion to substrate is rate limiting. Next to a fundamental insight into the kinetics of atmospheric pressure spatial ALD, this model can be used for design optimization of new spatial ALD reactors. Furthermore, the model shows that the maximum alumina deposition rates obtainable with spatial ALD are in the order of several nm/s. @ 2013 American Vacuum Society. [http://dx.doi.org/10.1116/1.4756692]
\end{abstract}

\section{INTRODUCTION}

The last few years have seen major progress in the development of spatial atomic layer deposition (ALD). ${ }^{1}$ Whereas for conventional ALD the precursors are dosed one by one, separated in time by a purge or pump step, in spatial ALD the precursors are dosed simultaneously and continuously, but separated in space. The main advantages of spatial ALD are the high deposition rate that can be achieved $(\mathrm{nm} / \mathrm{s}$ for alumina, ${ }^{2}$ as compared to $\sim \mathrm{nm} / \mathrm{min}$ for conventional ALD), the possibility to conduct atmospheric pressure deposition, and the absence of parasitic deposition in the reaction chamber. One of the first industrial applications exploited today for spatial ALD is surface passivation of crystalline silicon solar cells, ${ }^{3-5}$ and new applications, such as encapsulation, diffusion barriers, and roll-to-roll processing, are emerging. ${ }^{1}$

Figure 1 shows a schematic drawing of a typical spatial ALD reactor, containing an injector with precursor inlets and a moving substrate. Between and around the precursor inlets are gas-bearing inlets that act both as a diffusion barrier between the precursors and as a bearing between the injector and the substrate. The deposition rate of a spatial ALD reactor depends on the precursor exposure time (defined as the time a fixed point on the substrate is being exposed to a precursor) and the reaction rate. The latter is a function of deposition temperature, precursor partial pressures, surface site density, etc., culminating in an equilibrium reaction rate giving rise to the key-parameter in ALD, being the growth per cycle (GPC). The exposure time is determined by the geometry and dimensions of the spatial ALD injector, in conjunction with the relative movement speed of the

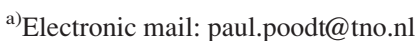

substrate with respect to the injector. In an ideal spatial ALD reactor, the precursor exposure times, determined by the design of the injector, should be optimized to the deposition kinetics of the ALD reaction, in order to not only avoid unnecessary long cycle times (decreasing the net deposition rate) but also avoid nonuniform deposition due to the variations in precursor partial pressure, gas flows, and exposure times. So, an in-depth knowledge of the ALD reaction kinetics is essential for optimizing the design of new spatial ALD reactors.

With this purpose in mind, we have investigated the deposition kinetics of spatial ALD. As a model system, the trimethylaluminum (TMA) and $\mathrm{H}_{2} \mathrm{O}$ process to form alumina was used. The GPC as a function of the main kinetic parameters (temperature, precursor partial pressures, and exposure times) has been experimentally determined, down to very short exposure times. A kinetic framework model has been developed, which is used as a tool to analyze the experimental data, resulting in a descriptive model of the alumina spatial ALD reaction. This model is validated by comparison with experimental data obtained with an injector with differently sized precursor inlets. Furthermore, the model will be used to get an estimate of what the maximum obtainable deposition rate of spatial ALD can be.

\section{EXPERIMENT}

All experiments described in this work were performed on a rotary spatial ALD reactor, described in detail in Ref. 2. The separate reaction zone inlets are incorporated in a round reactor head, surrounded and separated by gas-bearing planes [Fig. 2(a)]. Narrow slits in the inlets deliver the reactive gasses to the substrate. The reactor head is mounted on top of a rotating substrate table [Fig. 2(b)]. The gas bearing 


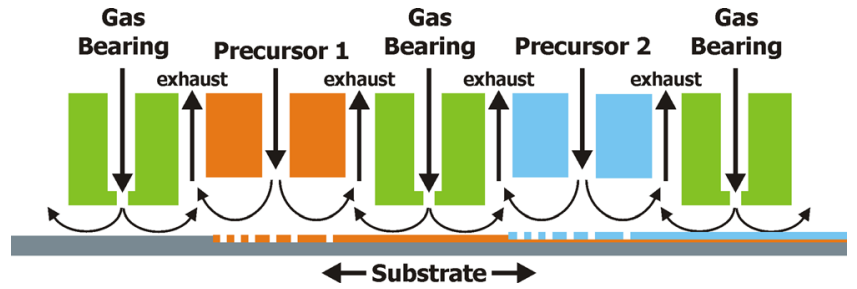

FIG. 1. (Color online) Schematic drawing of a spatial ALD reactor, where the precursor half-reaction zones are separated by gas bearings. By horizontally moving the substrate back and forth underneath the reactor, the two half-reactions will take place subsequently, forming an ALD monolayer.

is formed by flowing pressurized $\mathrm{N}_{2}$ through small holes $(0.2 \mathrm{~mm}$ diameter) located on the gas-bearing surface. When placed over the substrate, a gap between the substrate and the gas-bearing planes of $\sim 20 \mu \mathrm{m}$ is formed. The corresponding gap height between the substrate and the inlets is $\sim 200 \mu \mathrm{m}$. The entire construction is mounted in a convection oven, capable of heating up to $400^{\circ} \mathrm{C}$.

The injector contains two sorts of inlets [Fig. 2(a)]; long inlets being $45 \mathrm{~mm}$ long and $10 \mathrm{~mm}$ wide with their center at a radius of $37 \mathrm{~mm}$, used for larger deposition areas, and short inlets being $15 \mathrm{~mm}$ long, $7 \mathrm{~mm}$ wide with their center at a radius of $43 \mathrm{~mm}$. Unless stated otherwise, the short inlets were used in this work.

In situ reflectometry was used to measure the film thickness during deposition. A Laytec EpiTT reflectometer (Laytec AG, Berlin, Germany) was used for this purpose, with a $405 \mathrm{~nm}$ wavelength light beam being reflected perpendicular from the substrate. Because of thin-film interference, oscillations in the reflected intensity will occur from which the film thickness, and consecutively the deposition rate, can be calculated by fitting the reflected intensity to an optical model. Though not as accurate as ellipsometry, reflectometry is a fast-response technique, which is important when using very

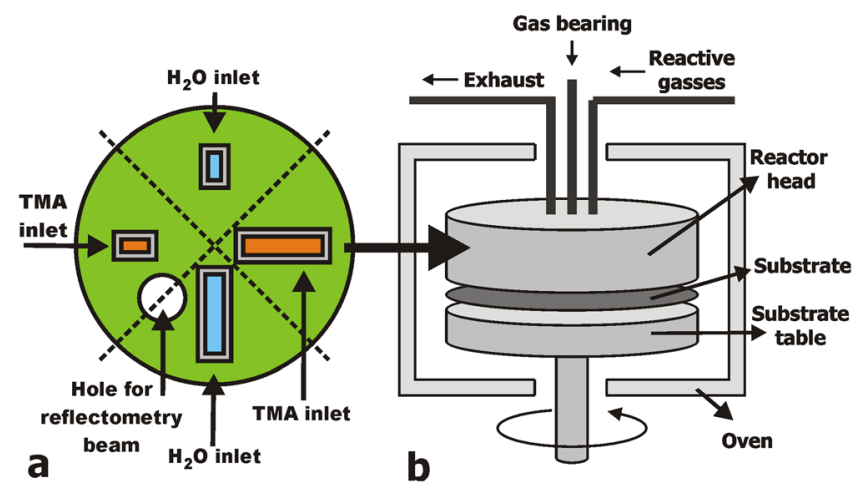

FIG. 2. (Color online) (a) Schematic drawing of the bottom side of the spatial ALD reactor head, where the TMA (orange) and water half-reaction zones (blue) are integrated into inlets surrounded by exhaust zones and gasbearing planes (green). Two sizes of inlets can be used for different deposition areas. A hole was placed in the injector to allow for a light beam to be reflected from the substrate in order to conduct in situ film thickness measurements with reflectometry. (b) Schematic drawing of the reactor. The reactor head and rotating substrate table with the substrate in between are placed in an oven. The substrate table is rotated by a servo-motor, connected by a drive shaft. The process and waste gas lines are connected to the reactor head through an opening in the top of the oven. short cycle times. Additional ex situ calibration of the data was however done by spectroscopic ellipsometry. The reflectometer light beam was positioned at a radius of $40 \mathrm{~mm}$.

All processes were performed at atmospheric pressure. Deposition temperatures were varied between 90 and $250{ }^{\circ} \mathrm{C}$. TMA (Akzo Nobel HPMO, semiconductor grade) and deionized water were used as precursors, being supplied by bubblers, where the partial pressures of both precursors was set by setting the bubbler temperature (setting the vapor pressure), the flow through the bubbler, and the dilution flow. The total volume flow in all cases and for both precursors was $1 \mathrm{slm}$ per inlet, and partial pressures of 1-10 mbar for TMA and 10-120 mbar for water were used. A 150-mm diameter, $0.7 \mathrm{~mm}$ thick, double-sided polished Si (100) wafer was used as substrate. The exposure time can be calculated by

$$
t=W / 2 \pi r v
$$

with $W$ is the width of the precursor inlet, $r$ is the radius where the film thickness is being measured, and $v$ is the rotation frequency. The maximum rotation frequency used is $50 \mathrm{~Hz}$, corresponding to a minimum exposure time of $0.56 \mathrm{~ms}$ for both the TMA and water inlets.

\section{KINETIC MODEL}

There are many examples in literature on modeling of the ALD deposition reaction, ranging from first-principle studies on precursor-substrate interactions, geometric analyses, to mechanistic kinetic models. ${ }^{6,7}$ However, all of them concern conventional ALD at low pressure. In this section, a kinetic framework is developed for the spatial ALD reaction at atmospheric pressure, which will be used as tool to analyze the experimental data.

Consider a typical four-step ALD reaction consisting of (I) - adsorption of precursor A onto the substrate, (II) - $\mathrm{a}$ purge step, (III) - adsorption of precursor B onto the substrate, and (IV) - the second purge step. Because of the nature of the ALD reaction, the reaction kinetics can be described by a number of discrete, separate rate equations, one for each reaction step. The total deposition rate is then given by some combination of all rate equations. Each reaction step can be described in terms of the surface coverage $\theta$, giving the number of surface sites covered by precursor molecules, normalized by the total number of available surface sites. It is a function of temperature, precursor partial pressure, and the reaction time, or

$$
\theta=\theta(T, p, t)
$$

Equation (2) for each reaction step can be obtained by solving the rate equation of each individual reaction step: the net uptake of precursor A in reaction step (I), the remainder of A after possible desorption in step (II), the net uptake of precursor B in step (III), and the remainder or B after possible desorption in step (IV). The total amount of deposited molecules in one reaction cycle $M$ is then given by 


$$
M=\left[\mathbf{S}_{0}\right] \theta_{1}+\left[\mathbf{S}_{1}\right] \theta_{2}=\left[\mathbf{S}_{0}\right] \theta_{1}+\left[\mathbf{S}_{0}\right] \theta_{1} \theta_{2},
$$

with $\theta_{1}$ and $\theta_{2}$ the net surface coverage of precursors $A$ and B after step (I) and (II), and (III) and (IV), respectively, and $\left[S_{0}\right]$ and $\left[S_{1}\right]$ the number of available surface sites at the beginning of the cycle and after steps (I) and (II), respectively.

Equation (3) implies that the total molecular uptake per cycle depends on the starting condition regarding available surface sites. In other words, the surface termination of the substrate (either A-terminated, B-terminated, or some mixture of the two) would determine the GPC. This is indeed true for the first few cycles, but after a certain number of cycles, the molecular uptake per reaction step reaches a constant value at fixed temperature-, partial pressure-, and exposure time values, as shown by Park et $a l^{8}{ }^{8}$ This corresponds to an expression for the GPC in terms of $\theta_{1}$ and $\theta_{2}$ according to

$$
\mathrm{GPC}=\mathrm{GPC}_{\mathrm{sat}}\left(\theta_{1} \theta_{2}\right) /\left(\theta_{1}+\theta_{2}-\theta_{1} \theta_{2}\right),
$$

with $\mathrm{GPC}_{\text {sat }}$ the saturated GPC, obtained after long exposure times.

As a case example, a simple adsorption reaction is discussed, where a precursor A adsorbs on and desorbs from a substrate with surface sites $\mathrm{S}$. The reaction equation is given by

$$
\mathrm{S}+\mathrm{A} \leftrightarrow \mathrm{SA},
$$

with $k_{a}$ and $k_{d}$ the reaction coefficient for the forward adsorption and backward desorption reaction, consecutively. The rate equation for reaction (5) is given by

$$
\partial[\mathrm{SA}] / \partial t=k_{a}[\mathrm{~A}][\mathrm{S}]-k_{d}[\mathrm{SA}],
$$

with $[\mathrm{SA}],[\mathrm{A}]$, and $[\mathrm{S}]$ the concentrations of the SA, A and S, respectively. In Eq. (6), [A] can be substituted by the precursor partial pressure, and the entire equation can be rewritten in terms of surface coverage, with $[\mathrm{S}]=\left[\mathrm{S}_{0}\right]-[\mathrm{SA}]$ and $\theta_{\mathrm{SA}}=[\mathrm{SA}] /\left[\mathrm{S}_{0}\right]$, giving

$$
\partial \theta_{\mathrm{SA}} / \partial t=k_{a} p_{A}\left(1-\theta_{\mathrm{SA}}\right)-k_{d} \theta_{\mathrm{SA}},
$$

with $p_{A}$ the partial pressure of precursor $A$. The solution to Eq. (7) is

$$
\theta_{\mathrm{SA}}=K p_{A} /\left(1+K p_{A}\right)\left(1-\exp \left[-\left(k_{d} p_{A}+k_{d}\right) t\right]\right),
$$

with $K p_{A} /\left(1+K p_{A}\right)$ the Langmuir isotherm and $K=k_{a} / k_{d}$, where the reaction coefficients contain the temperature dependency via the Arrhenius relation $k=A \exp \left[-E_{a} / k T\right]$.

As a more complex example, reaction (9) is considered, where after the adsorption step, a consecutive reaction takes place to form $\mathrm{SB}$, the reactive site for the next half-reaction

$$
\begin{aligned}
& \mathrm{S}+\mathrm{A} \rightarrow \mathrm{SA}, \\
& \mathrm{SA} \rightarrow \mathrm{SB},
\end{aligned}
$$

with $k_{1}$ and $k_{2}$ the reaction coefficient for the first and second reaction, consecutively, where desorption is ignored for simplicity. The rate equation and solutions are given by

$$
\begin{gathered}
\partial \theta_{\mathrm{SA}} / \partial t=k_{1} p_{A}\left(1-\theta_{\mathrm{SA}}-\theta_{\mathrm{SB}}\right)-k_{2} \theta_{\mathrm{SA}} \\
\partial \theta_{\mathrm{SB}} / \partial t=k_{2} \theta_{\mathrm{SA}}, \\
\theta_{\mathrm{SB}}=1-\left(k_{1} p_{A}\right) /\left(k_{1} p_{A}-k_{2}\right) \exp \left[-k_{2} t\right] \\
\quad+k_{2} /\left(k_{1} p_{A}-k_{2}\right) \exp \left[-k_{1} p_{A} t\right] .
\end{gathered}
$$

Now, in this example, two exponential terms appear.

Many more, and more realistic, reaction schemes can be considered. For instance, Ref. 9 shows that TMA can adsorb and consecutively undergo several reactions, forming dimethyl-aluminum, monomethyl-aluminum, and nonmethylated aluminum moieties, each with its own reactivity toward water. Including all these reaction steps in the rate equation can make it very challenging to find analytical solutions. However, it can be stated that the surface coverage function can be given in general terms by

$$
\theta / \theta_{\text {sat }}=1-\Sigma \alpha \exp [-f(p, T, t)]
$$

with $\alpha$ being a term depending on temperature and precursor partial pressure, and $f$ a function of precursor partial pressure, temperature, and exposure time. The number of exponential terms in the summation is given by the number of elementary reaction steps [e.g., 1 in Eq. (8) and 2 in Eq. (11)]. Though, it can be assumed that one of all possible reaction steps is rate limiting, so that Eq. (12) can be approximated by a single exponential term describing the rate-limiting reaction kinetics.

If solutions of Eq. (12) are substituted in Eq. (4), a quite elaborate equation is obtained. As a consequence, fitting this equation to experimental data is problematic, as no unique solutions for $\theta_{1}$ and $\theta_{2}$ can be obtained. However, in can be assumed that under given conditions, the reaction rate of one half reaction is lower than the other and can be considered to be rate limiting. For instance, if $\theta_{1}<\theta_{2}, \theta_{1}$ is rate limiting $\left(\theta_{\mathrm{RL}}\right)$ and Eq. $(4)$ reduces to

$$
\mathrm{GPC} \approx \mathrm{GPC}_{\mathrm{sat}} \theta_{\mathrm{RL}},
$$

with $\theta_{\mathrm{RL}}$ the surface coverage function of the rate-limiting half-reaction.

Now, with these assumptions in mind and according to Eq. (12), the function $f(p, T, t)$ can be obtained from the experimental data by calculating

$$
f(p, T, t)=\ln \left[1-\mathrm{GPC} / \mathrm{GPC}_{\mathrm{sat}}\right] .
$$

The dependencies of $f$ on $p, T$, and $t$ can be investigated experimentally, to obtain a kinetic model to describe the ALD process.

\section{RESULTS AND DISCUSSION}

\section{A. Results}

Figure 3 shows the GPC of alumina as a function the partial pressure of TMA and $\mathrm{H}_{2} \mathrm{O}$, respectively, measured at a fixed exposure time of $6 \mathrm{~ms}$ and a deposition temperature of $200{ }^{\circ} \mathrm{C}$. It shows behavior as expected for a self-limiting ALD reaction; at a certain partial pressure, the GPC saturates 

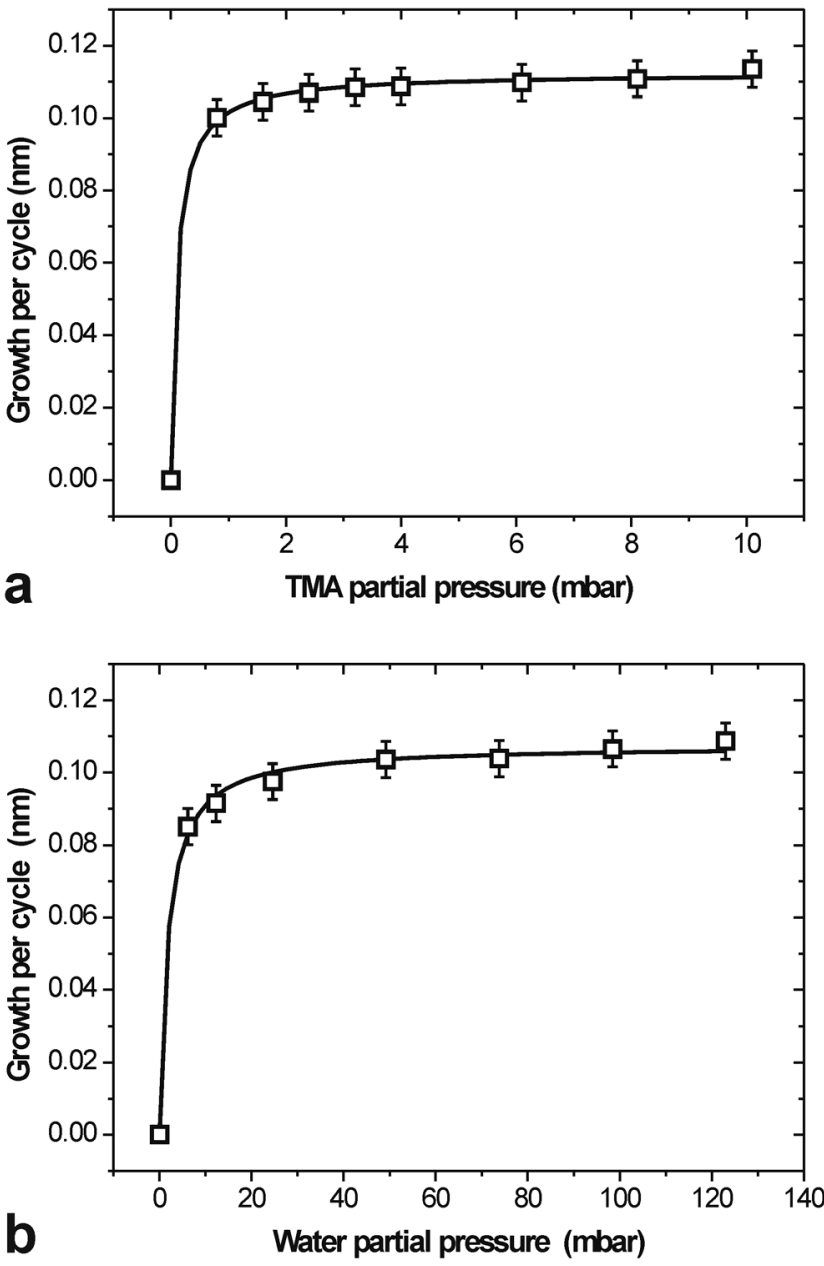

FIG. 3. Alumina growth per cycle as a function of the TMA partial pressure (a) and water partial pressure (b) at an exposure time of $6 \mathrm{~ms}$ and a deposition temperature of $200^{\circ} \mathrm{C}$. The data were fitted by the Langmuir isotherm $K p /(1+K p)$, with $K=9.45$ and $0.55 \mathrm{mbar}^{-1}$ for (a) and (b), respectively.

and using higher partial pressures has minor effects on the GPC. The data were fitted by the Langmuir isotherm: GPC/ $\mathrm{GPC}_{\mathrm{sat}}=K p /(1+K p)$, with $K$ the Langmuir adsorption constant being 9.45 and $0.55 \mathrm{mbar}^{-1}$ for TMA and water, respectively. Apparently, the water half-reaction has a higher activation energy than the TMA half-reaction, leading to a lower value of $K$. As a compensation, much higher water partial pressures are required to obtain self-limiting behavior. For the remainder of the investigation, the TMA and water partial pressures were set at sufficiently high values to make sure the self-limiting regime was obtained (i.e., 5 mbar for TMA and 100 mbar for $\mathrm{H}_{2} \mathrm{O}$ ).

Figure 4 shows the GPC as a function of TMA/ $\mathrm{H}_{2} \mathrm{O}$ exposure time for deposition temperatures of 150, 200, and $250{ }^{\circ} \mathrm{C}$. A considerable number of data points were measured at very short exposure times in the undersaturated regime. Although this is not considered to be the optimum ALD condition, this part of the GPC curve provides much information about the reaction kinetics. The GPC shows behavior as expected of ALD: a rapid increase of thickness with time, after which the GPC saturates as a result of the self-limiting behavior of ALD. Note that the GPC reaches its saturation

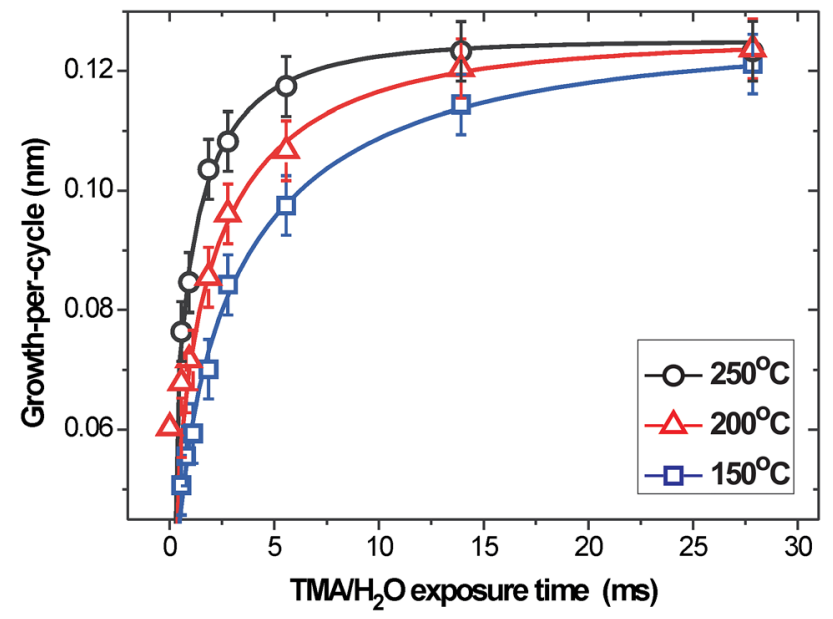

FIG. 4. (Color online) Growth per cycle as a function of TMA/ $\mathrm{H}_{2} \mathrm{O}$ exposure time for deposition temperatures from $150^{\circ} \mathrm{C}$ to $250^{\circ} \mathrm{C}$, at precursor partial pressures of 5 mbar for TMA and 100 mbar for $\mathrm{H}_{2} \mathrm{O}$.

value already at very short exposure times, in the order of a few tens of milliseconds. At the shortest obtainable exposure time $(0.55 \mathrm{~ms})$ at $200^{\circ} \mathrm{C}$, the GPC is already half the saturation value. Furthermore, it can be seen that at lower deposition temperatures, longer exposure times are required to reach the saturated value of the GPC.

Figure 5(a) shows $\ln (1-\mathrm{GPC})$ versus the $\mathrm{TMA} / \mathrm{H}_{2} \mathrm{O}$ exposure time, following the analysis described in Sec. III. No linear relationship is obtained; however, Fig. 5(b) shows that $[\ln (1-\mathrm{GPC})]^{2}$ versus the $\mathrm{TMA} / \mathrm{H}_{2} \mathrm{O}$ exposure time does show a linear relationship, indicating that Eq. (12) can be written as

$$
\mathrm{GPC} / \mathrm{GPC}_{\mathrm{sat}}=1-\exp [-a \sqrt{ } t]
$$

We were able to fit all our experimental data to Eq. (15) using only $a$ as fit parameter, where $a$ contains the temperature dependence of the GPC. It can be assumed that the temperature dependence of $a$ can be described by an Arrhenius relation, being $a=A \exp [-E / R T]$, with $A$ a pre-exponential factor, $E$ an activation energy, $R$ the gas constant, and $T$ the deposition temperature in Kelvin. Figure 6 shows the Arrhenius plot of $a$ vs $1 / T$. From this plot, $A$ is determined to be $397 \mathrm{~s}^{-1}$ and $E / R=1250.5 \mathrm{~K}$.

From the experimental data and the kinetic framework, we have now obtained a descriptive model of the GPC as a function of precursor exposure time, at sufficiently high precursor partial pressures. This model was validated using a longer set of precursor inlets as discussed in Sec. II. These inlets are longer in order to get deposition on a larger area. All partial pressures and volume flows were kept the same as for the short inlets, meaning that volume flow divided by the inlet is approximately four times less. To exaggerate possible nonuniformity effects, a high rotation frequency was used $(10 \mathrm{~Hz})$ at which a radial gradient in thickness is expected due to the radial variation in linear velocity and precursor exposure time. Figure 7 shows the experimentally obtained radial GPC variation, as measured by ellipsometry, and the expected GPC calculated from the model. It can be seen that at lower radii, the model slightly overestimates the actual 

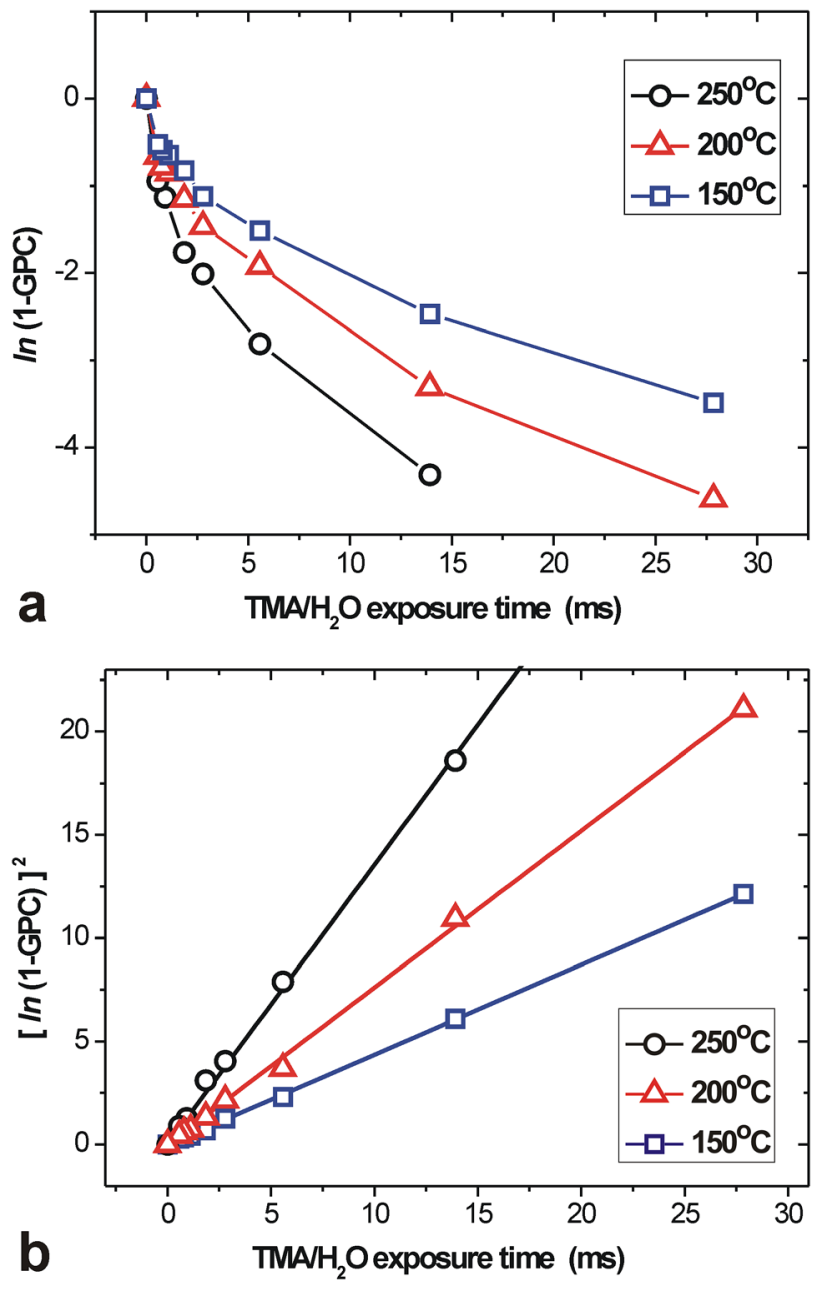

FIG. 5. (Color online) Analysis of the experimental data according to the kinetic model at precursor partial pressures of 5 mbar for TMA and 100 mbar for $\mathrm{H}_{2} \mathrm{O}$. (a) $\ln (1-\mathrm{GPC})$ vs $\mathrm{TMA} / \mathrm{H}_{2} \mathrm{O}$ exposure time where no linear time dependency is observed. (b) $[\ln (1-\mathrm{GPC})]^{2}$ vs TMA $/ \mathrm{H}_{2} \mathrm{O}$ exposure time.

GPC, which is likely caused by the lower net volume flow. However, the trend is accurately described up to larger radii, where the experimental GPC deviates more, with lower values than predicted by the model. This effect can be attributed

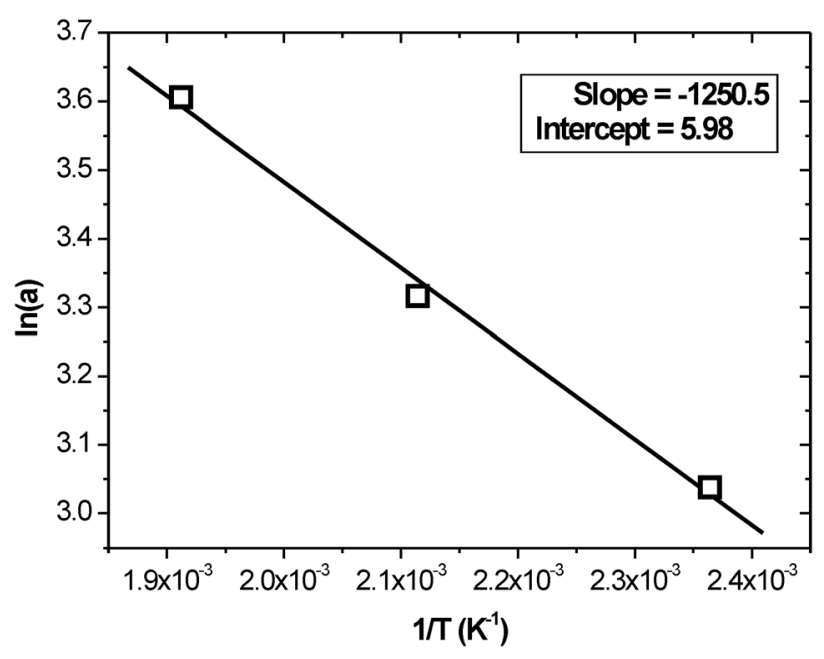

FIG. 6. Arrhenius plot of the fit parameter $a$ vs $1 / T$. $A$ is determined to be $397 \mathrm{~s}^{-1}$ and $E / R=1250.5 \mathrm{~K}$.

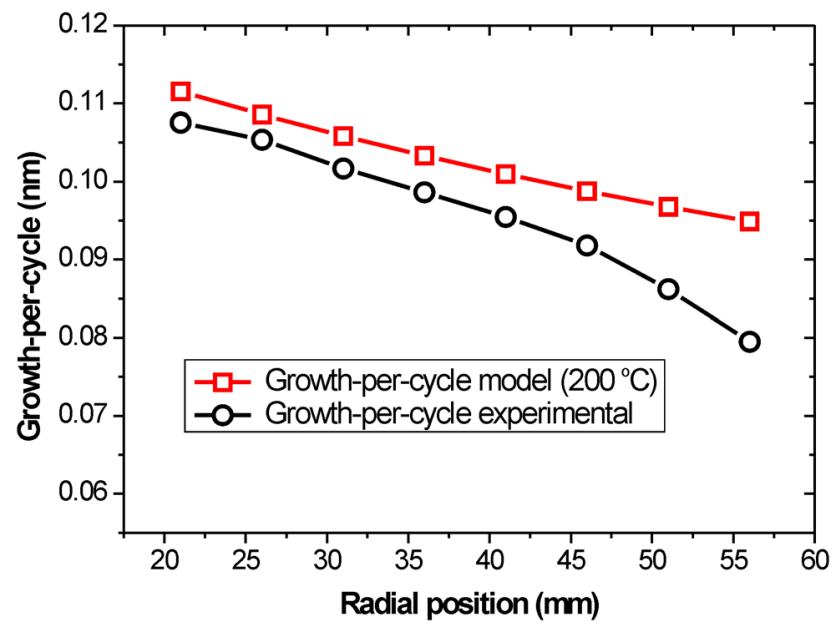

FIG. 7. (Color online) Experimentally obtained radial GPC variation for the elongated precursor inlets, and the expected GPC calculated from the model. At lower radii, the model slightly overestimates while the trend is accurately described. At larger radii, the experimental GPC deviates more to lower values than predicted by the model, likely to be caused by the presence of the exhaust at a position of $45 \mathrm{~mm}$.

to the presence of the exhaust at a position of $45 \mathrm{~mm}$, leading to slightly lower effective precursor exposure times. If the model would be used in a combination with finite-element modeling including all flows and pressure gradients, it is very likely that these kinds of effects can be explained by the kinetic model as well.

The model can also be used as input for injector design and optimization. As an example, the required dimensions and geometry of a spatial ALD injector to obtain a desired deposition rate can be calculated from the model. Furthermore, an estimate can be made on what the maximum obtainable deposition rates for spatial ALD can be. These can be calculated from the minimum required cycle time to obtain the desired level of saturation. A complete saturated reaction requires longer cycle times than when a slight undersaturation is allowed, leading to lower deposition rates. However, the properties of the film can be influenced by the level of saturation as well. Figure 8(a) shows the minimal precursor exposure time needed to obtain a certain level of saturation as a function of deposition temperature, calculated with the model, where $99 \%$ means $\mathrm{GPC}=0.99 \mathrm{GPC}_{\mathrm{sat}}$. From these numbers, the maximum deposition rate can be estimated, for instance, by assuming that the cycle time is four times the calculated minimum exposure time (once for TMA, once of $\mathrm{H}_{2} \mathrm{O}$ and twice for the purge), dividing the GPC by the cycle time, as shown in Fig. 8(b). It can be seen that, depending on the deposition temperature and the allowed level of saturation, the maximum deposition rate will be in the order of one to several $\mathrm{nm} / \mathrm{s}$. If multiple slotpairs would be combined in-line, the net deposition rate can be even increased accordingly.

\section{B. Discussion}

The $\sqrt{ } t$ relationship in the exponential term of Eq. (15) is a bit surprising, as it does not automatically follow from the rate equations as described previously. However, there are 

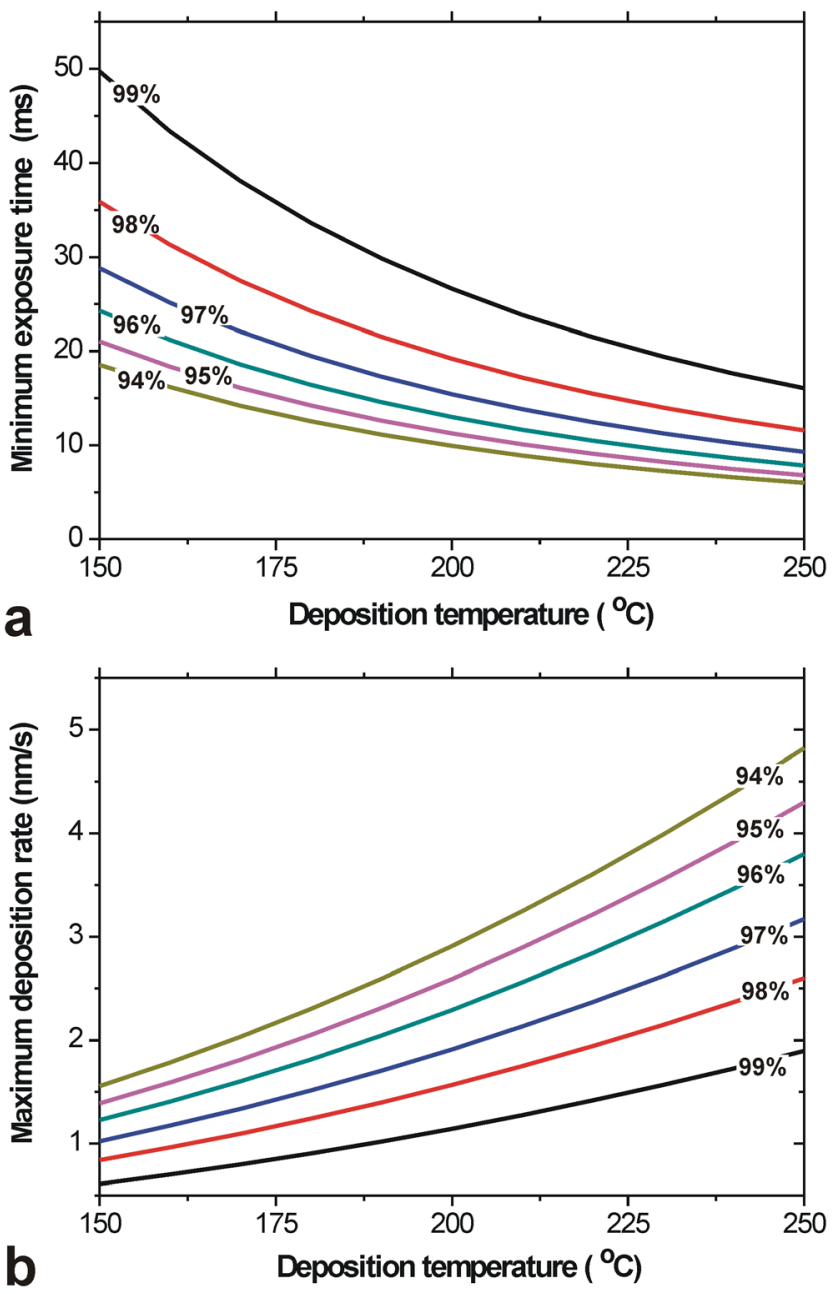

FIG. 8. (Color online) (a) Minimal precursor exposure time needed to obtain a certain level of saturation as a function of deposition temperature, calculated with the model, where $99 \%$ means GPC $=0.99 \mathrm{GPC}_{\text {sat }}$. (b) The maximum deposition rate as a function of deposition temperature, calculated from (a).

several, well-known phenomena where $\sqrt{ } t$-dependencies are observed. First, the thickness of a laminar boundary layer that is formed when a gas flows along a surface is proportional to $1 / \sqrt{ } v$, with $v$ the flow velocity of the gas, which corresponds to a $\sqrt{ } t$-dependency. ${ }^{10}$ The thickness of boundary layer is known to influence mass and heat transport to and from the substrate, ${ }^{11}$ as was, for instance, also shown by Mousa et al. ${ }^{12}$ for ALD at atmospheric pressure. However, because of the narrow gap between the injector and the substrate, a Poiseuille flow is more likely to form then a laminar boundary layer. Furthermore, due to the rapid movement of the substrate with respect to the injector, the Poiseuille flow will be perturbed by viscous drag, resulting in a so-called Poiseuille-Couette flow regime, ${ }^{13}$ that might for instance drag along nitrogen from the gas-bearing underneath the precursor inlets. This effect would be most pronounced at high substrate rotation velocities, thus at short exposure times. However, the $\sqrt{ } t$-dependency has been observed for all exposure time ranges, including long exposure times.

Another phenomenon where $\sqrt{ } t$-dependencies are observed is in the cases of diffusion limited mass transport, for example, dendritic crystal growth. ${ }^{14}$ In the case where there is a flux of precursor molecules toward a substrate (=deposition) and there is a constant supply of precursors at a given distance from the substrate (e.g., the inlet), solving Fick's laws of diffusion gives a time-dependent concentration gradient, where the concentration (or partial pressure) $p$ at each point varies as $p(t) \propto p_{\text {inlet }} /((D t)$ with $D$ the diffusion coefficient. ${ }^{15}$ In the rate equations [e.g., Eq. (7)], it is actually the interface partial pressure that needs to be used instead of the inlet partial pressure. Solving the rate equation with the properly substituted surface partial pressure results in

$$
\mathrm{GPC} \propto 1-\exp \left[-f\left(k, D, p_{\text {inlet }}\right) 、 t\right],
$$

with $f\left(k, D, p_{\text {inlet }}\right)$ a function of the kinetic coefficient, the diffusion coefficient, and the precursor partial pressure at the inlet, corresponding to the experimentally observed $\sqrt{ } t$ dependency.

The question remains whether the observed $\sqrt{ } t$-dependency is typical for spatial ALD in general or maybe for just for ALD at atmospheric pressure and/or for very small gaps between the injector and the substrate. It is known that pressure can influence mass transport; the diffusion coefficient reduces with pressure and a diffusion limited regime will be earlier achieved at atmospheric pressure than at low pressure. As a validation, these experiments should be compared with similar experiments for spatial and conventional ALD at low and atmospheric pressure.

Whether Eq. (15) is valid for other conditions than investigated in this work requires further investigations. It is known, however, that for the TMA/ $\mathrm{H}_{2} \mathrm{O}$ reaction at temperatures $<100^{\circ} \mathrm{C}$, the purge step after the water half-reaction becomes rate-limiting, as at these temperatures the water sticking coefficient is relatively high, leading to excess multilayer(s) of water adsorbed on the substrate. ${ }^{12,16,17}$ If the excess water is not sufficiently desorbed in the purge step, it will react with TMA in the consecutive TMA half-reaction, leading to an undesired CVD component in the ALD reaction.

Another interesting case is spatial ALD of other materials, for example, (multi)crystalline films like $\mathrm{ZnO}$. In this case, next to the deposition kinetics, the crystallization kinetics have to be included in the analysis as well. The crystallization kinetics might not necessarily influence the GPC too much, but it can for instance determine the grain size and orientation in the film. ${ }^{18}$ As these properties are important for the electrical and optical properties of the film, the crystallization kinetics needs to be investigated as well to optimize the performance of the deposited films.

\section{SUMMARY AND CONCLUSIONS}

To conclude, we have investigated the deposition kinetics of spatial ALD of alumina from TMA and $\mathrm{H}_{2} \mathrm{O}$ at atmospheric pressure. A kinetic model was developed that describes the GPC as a function of the main kinetic parameters. It was found that the water half-reaction is rate limiting, and the observation of a $\sqrt{ } t$-dependency points at diffusion limited mass transport of the precursor to the substrate. Next 
to a fundamental insight into the kinetics of atmospheric pressure spatial ALD, this model can be used for design optimization of new spatial ALD reactors.

${ }^{1}$ P. Poodt, D. C. Cameron, E. Dickey, S. M. George, V. Kuznetsov, G. N. Parsons, F. Roozeboom, G. Sundaram, and A. Vermeer, J. Vac. Sci. Technol. A 30, 010802 (2012), and references therein.

${ }^{2}$ P. Poodt, A. Lankhorst, F. Roozeboom, K. Spee, D. Maas, and A. Vermeer, Adv. Mater. 22, 3564 (2010).

${ }^{3}$ B. Vermang, A. Rothschild, A. Racz, J. John, J. Poortmans, R. Mertens, P. Poodt, V. Tiba, and F. Roozeboom, Prog. Photovoltaics 19, 733 (2011).

${ }^{4}$ F. Werner, B. Veith, V. Tiba, P. Poodt, F. Roozeboom, R. Brendel, and J. Schmidt, Appl. Phys. Lett. 97, 162103 (2010).

${ }^{5}$ P. Brand, Y. Veschetti, V. Sanzone, R. Cabal, X. Parges, K. Vanormelingen, and P. Vermont, Proceedings of the 37th IEEE Photovoltaic Specialist Conference, Seattle, June 2011.

${ }^{6}$ S. D. Elliot, Semicond. Sci. Technol. 27, 074008 (2012), and references therein.

${ }^{7}$ R. L. Puurunen, J. Appl. Phys. 97, 121301 (2005), and references therein.
${ }^{8}$ H. S. Park, J. S. Min, J. W. Lim, and S. W. Kang, Appl. Surf. Sci. 158, 81 (2000).

${ }^{9}$ S. D. Elliot and J. C. Green, J. Mater. Chem. 14, 3246 (2004).

${ }^{10} \mathrm{H}$. Schlichting, Boundary Layer Theory (McGraw-Hill, New York, 1979).

${ }^{11}$ H. O. Pierson, Handbook of Chemical Vapor Deposition, 2nd ed. (William Andrew, Norwich, 1999).

${ }^{12}$ M. B. M. Mousa, C. J. Oldham, J. S. Jur, and G. N. Parsons, J. Vac. Sci. Technol. 30, 01A155 (2012).

${ }^{13}$ P. K. Kundu, I. M. Cohen, and H. H. Hu, Fluid Mechanics (Academic, Waltham, 2004).

${ }^{14}$ M. E. Glicksman, Crystal Growth: From Fundamentals to Technology, edited by G. Muller, J. J. Metois, and P. Rudolph (Elsevier, Amsterdam, 2004), pp. 112-137.

${ }^{15}$ J. Crank, The Mathematics of Diffusion (Clarendon, Oxford, 1979).

${ }^{16}$ P. S. Maydannik, T. O. Kaariainen, and D. C. Cameron, J. Vac. Sci. Technol. 30, 01A122 (2012).

${ }^{17}$ P. Poodt, R. Knaapen, A. Illiberi, F. Roozeboom, and A. van Asten, J. Vac. Sci. Technol. 30, 01 A142 (2012).

${ }^{18}$ A. Illiberi, F. Roozeboom, and P. Poodt, ACS Appl. Mater. Interfaces 4, 268 (2012). 